\title{
Extraction and Characterization of Rice Bran Polysaccharides and Their Derivative Preparation and Antioxidant Activity
}

\author{
Gangliang Huang \\ Active Carbohydrate Research Institute, Chongqing Normal University, Chongqing 401331, \\ China
}

E-mail: huangdoctor226@163.com

\begin{abstract}
Absrtact: The crude polysaccharide of rice bran polysaccharide was extracted with water from defatted rice bran, and the optimal reaction conditions of the experiment were determined. The reaction temperature is $100^{\circ} \mathrm{C}$, the reaction time is $5 \mathrm{~h}$, the solid-liquid ratio is 1:10; the concentration ratio of polysaccharide to Sevag reagent is $2: 1$, and rice polysaccharide is precipitated by ethanol insoluble property and ethanol. The ethanol concentration ratio is $3: 1$. Using the methods and conditions of this experiment, the maximum polysaccharide yield is $2.18 \%$. Then the chemical structure of rice bran polysaccharide was analyzed by IR, UV and 13CNMR methods. Three rice bran polysaccharide derivatives were prepared and characterized: carboxymethylated rice bran polysaccharide, phosphorylated rice bran polysaccharide and acetylated rice bran polysaccharide. Also studied the antioxidant activity of rice bran polysaccharide and its derivatives (hydroxy radical ion scavenging ability, superoxide anion scavenging ability, anti-lipid peroxidation ability, reducing ability), and found that phosphorylated rice bran polysaccharide has good activity. The acetylated rice bran polysaccharide may weaken the original activity.
\end{abstract}

Key words: Rice bran polysaccharide; extraction; structure; rice bran polysaccharide derivative; antioxidant activity

\section{Introduction}

Rice is a member of the grass family Gramineae and is the second largest food crop in the world. Global rice production accounts for about $37 \%$ of total grain output. At present, the annual global rice output has reached about 500 million tons, and it is still increasing year by year. China's rice planting area accounts for $1 / 4$ of the country's total grain planting area. The average annual total rice output is more than 200 million tons. Rice bran is a by-product of rice processing, which accounts for about $6 \%$ to $7.5 \%$ of rice quality.[1] In China, $1300-1400$ t of rice bran can be 
produced every year.

Rice bran polysaccharide (Rice bran polysaccharide (RBPs)) is a heteroglycan composed of $\alpha$-1,3-glucan as the main chain and a variety of monosaccharide units such as xylose, galactose, mannose, rhamnose, arabinose, and ribose as side chains. $[2-5]$

Rice bran is rich in a variety of active ingredients, such as fats, proteins, carbohydrates, oryzanol, vitamins, calcium, iron, magnesium, manganese, potassium, sodium, zinc and other essential nutrients for the human body.[6-9] Rice bran can be used to extract rice bran oil, make rice wax, rice bran, etc. These products have the effect of lowering blood cholesterol. Rice bran has replaced corn and other raw materials in animal and poultry feed, and there are many studies and reports on reducing feed cost and improving economic benefits. Rice bran has the functions of intestinal tract, appetizer, and qi, and can be used to treat beriberi, cancer, etc. [11-12].

A variety of biological polysaccharides have biological activity with development potential. Their functions include immunomodulation, anti-tumor, hypoglycemic, hypolipidemic, and anti-radiation. Plant polysaccharide research has attracted more and more attention. The international scientific community even proposes that the 21 st century is a polysaccharide century Scientific experiment research, antibacterial and antiviral, liver protection and other health effects. Therefore, plant polysaccharides have long been widely used in the field of public life such as the medical community, the catering community. [13-16]

Rice bran polysaccharide also has significant biological activity and health care functions. Studies at home and abroad have shown that rice bran polysaccharides have various active functions such as anti-tumor, hypoglycemic, cholesterol-lowering, anti-bacterial infection and immunity enhancement [17-19]. Unfortunately, at present, most rice bran has not been effectively used, because the lipase activity in rice bran is very high, which is easy to cause rice bran spoilage. Therefore, improving the extraction process of rice bran polysaccharides is of great significance to the utilization of rice bran. 


\section{Materials}

For rice bran, we chose the 2019 fresh autumn defatted rice bran provided by Hubei Fuhua Company.This batch of rice bran will be used within four months.

\section{Methods and Results}

\subsection{Methods}

Basic process of extraction and separation and purification of defatted rice bran polysaccharides:

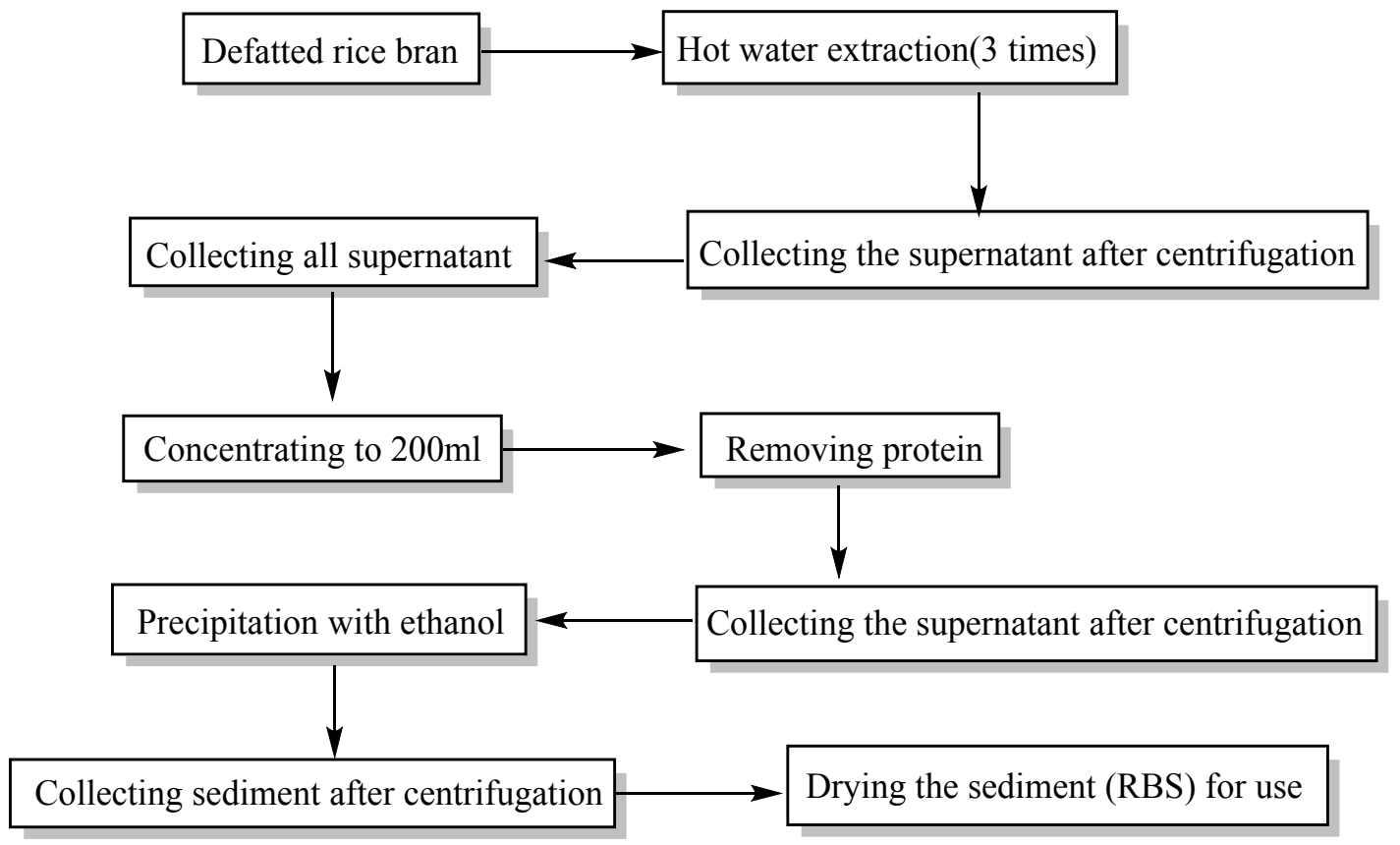

Fig.1 Rice bran polysaccharide preparation process

\subsubsection{Extraction, Separation and Purification of Rice Bran Polysaccharide}

$100 \mathrm{~g}$ of defatted rice bran has been weighed for the extraction of rice bran polysaccharides. The defatted rice bran and distilled water have been placed in a three-necked flask at a feed-water ratio of 1:10, and a magnetic stir bar has been placed in the mixture. After the defatted rice bran has been soaked in distilled water for 1 hour, the whole system was placed in a constant temperature water bath at $100^{\circ}$ 
C. The first extraction has been carried out after stirring and heating at $100{ }^{\circ} \mathrm{C}$ for 5 hours, centrifugation at $4000 \mathrm{r} / \mathrm{min}$ for $10 \mathrm{~min}$, and the supernatant has been collected. In the second extraction, $200 \mathrm{~mL}$ of distilled water has been added to the filter residue, it has been stirred and heated at $100^{\circ} \mathrm{C}$. for 1 hour, it has been centrifuged again at $4000 \mathrm{r} / \mathrm{min}$ for $10 \mathrm{~min}$, and the supernatant is collected. In the third extraction, 200 $\mathrm{mL}$ of distilled water has been added to the remaining filter residue, which has been stirred and heated at $100^{\circ} \mathrm{C}$. for 1 hour, and has been centrifuged at $4000 \mathrm{r} / \mathrm{min}$ for $10 \mathrm{~min}$ to collect the supernatant. All the collected supernatants that have been extracted three times are combined and concentrated to $200 \mathrm{~mL}$ of solution. The rice bran polysaccharide solution was sealed and stored in a refrigerator at $0-5^{\circ} \mathrm{C}$.

The Sevag reagent method was used to remove protein from rice bran polysaccharides. According to the literature [20], the concentrated crude rice bran polysaccharide solution and Sevag reagent were mixed in a ratio of 2:1. At this time, the protein removal rate is the highest.

$200 \mathrm{~mL}$ of rice bran crude polysaccharide solution, $100 \mathrm{~mL}$ of Sevag reagent was used to remove protein. The Sevag reagent in our experiment used $\mathrm{CHCl}_{3}$ : $\mathrm{CH}_{3}\left(\mathrm{CH}_{2}\right)_{3} \mathrm{OH}$ was 2: 1. It should be noted here that we have configured $120 \mathrm{~mL}$ of Sevag reagent, $80 \mathrm{~mL}$ of $\mathrm{CHCl}_{3}$ and $40 \mathrm{~mL}$ of $\mathrm{CH}_{3}\left(\mathrm{CH}_{2}\right)_{3} \mathrm{OH} .100 \mathrm{~mL}$ Sevag reagent was mixed with $200 \mathrm{ml}$ the crude rice bran polysaccharide concentrated solution. After the mixing was completed, a magnetic stirrer was used to stir for 30 minutes, in order to fully react the crude polysaccharide solution with Sevag reagent. After the reaction, it was allowed to stand for 30 minutes to separate the layers, and then centrifuged at $4000 \mathrm{r} / \mathrm{min}$ for $10 \mathrm{~min}$. The solution has been divided into three layers. The supernatant has been transferred into the beaker with a dropper, and the middle and lower solution are poured into the waste bottle for recovery. Then the supernatant was repeated the above operation twice to remove protein.

Taking advantage of the insoluble properties of rice bran polysaccharides, $95 \%$ ethanol was used to precipitate rice bran polysaccharides. After reading the reference[21-22], we know that 3 times the volume of 95\% ethanol is used to precipitate rice bran polysaccharides. The ethanol was stirred for 5 minutes to make it contact completely, and after standing for 5 hours, a light yellow flocculent precipitate was obtained, which was centrifuged at $4000 \mathrm{r} / \mathrm{min}$ for $10 \mathrm{~min}$. The bottom sediment was rice bran polysaccharide. The mortar containing the rice bran polysaccharide was placed in a vacuum freeze dryer for $12 \mathrm{~h}$, and the dried rice bran polysaccharide solid was ground into a powder. The weight of the rice bran polysaccharide powder was weighed and placed in a plastic tube. Waiting to be used.

\subsubsection{Determination of Polysaccharide Content}

The polysaccharide content was determined by the phenol sulfuric acid method [23].Preparation of standard curve: According to [24], a $100 \mathrm{mg} / \mathrm{L}$ glucose standard solution was prepared. Different volumes of glucose standard solutions were drawn 
into test tubes and filled with deionized water to $0.5 \mathrm{ml}(0.5 \mathrm{ml}$ deionized water was used as the blank control group). $0.50 \mathrm{~mL}$ of $5 \%$ phenol solution was added and mixed thoroughly, $2.5 \mathrm{~mL}$ of concentrated sulfuric acid was added and quickly shaken, and cooled at room temperature for 15 minutes to room temperature.Distilled water was used as a blank control group. The absorbance of glucose solutions with different mass concentrations at $490 \mathrm{~nm}$ (A) has been measured. The mass concentration of glucose has been taken as the abscissa and the absorbance has been taken as the ordinate. A standard curve has been drawn, and the regression equation has been calculated. The regression equation of Fig.2 is: $\mathrm{Y}=13.082 \mathrm{x}-0.0091, \mathrm{R} 2=0.997$. Finally, three parallel experiments are performed on each sample. The polysaccharide content can be calculated by the regression equation.

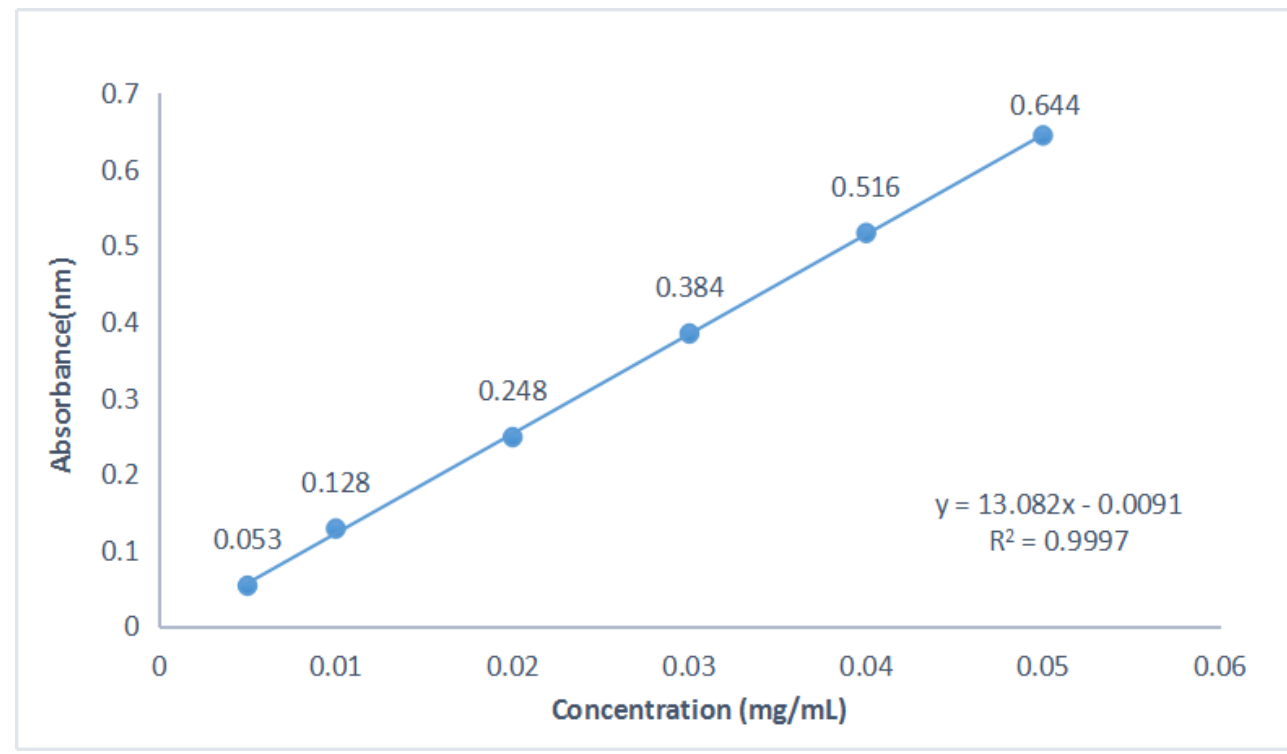

Fig.2 The standard curve

3.1.3 Preparation of carboxymethylated rice bran polysaccharide [25]

Carboxymethylated rice bran polysaccharide.At room temperature, $0.5 \mathrm{~g}$ of rice bran polysaccharides (RBPs) was added to $60 \mathrm{ml}$ of isopropanol and stirred for 30 minutes.Then, $30 \% \mathrm{NaOH}$ solution $(5.6 \mathrm{~mL})$ and TCA $(2.4 \mathrm{~g})$ were added to the mixture. And the mixture was stirred at $50^{\circ} \mathrm{C}$ for 3 hours. The reaction solution was adjusted to neutral with dilute hydrochloric acid, and then the dialysis bag was used in the distilled water for 3 days. The supernatantliquid was concentratedto $20 \mathrm{~mL}$. Add 3 times the volume of ethanol, centrifuge, and wash twice with alcohol. The precipitate was dissolved in distilled water and freeze-dried to obtain a white substance (CM-RBPs).

3.1.4 Preparation of phosphorylated rice bran polysaccharide 
Phosphorylated rice bran polysaccharide.RBPs $(0.5 \mathrm{~g})$ was suspended in $30 \mathrm{~mL}$ DMSO at room temperature with stirring for $8 \mathrm{~h}$. Then adding $6.5 \mathrm{~mL}$ pyridine to the mixture, stirring for $0.5 \mathrm{~h}$, and the reaction reagent $\mathrm{POCl}_{3}(2.5 \mathrm{~mL})$ were added dropwise.After the reaction, the mixture was cooled to room temperature and the $\mathrm{pH}$ value was adjusted to 7 with $1 \mathrm{~mol} / \mathrm{L} \mathrm{NaOH}$ solution. The mixtures were precipitated with ethanol (95\%), washed and then dialyzed with distilled water for $3 \mathrm{~d}$ to remove pyridine and salt.The supernatant was concentrated to $20 \mathrm{~mL}$, and add 3 times the volume of ethanol,then centrifuged, washed with alcohol for two times.And then the mixture was dried in a vacuum freezing dryer.Phosphorylated rice bran polysaccharide were collected as P-RBPs. The samples were stored in a desiccator at room temperature till for use.

\subsubsection{Preparation of acetylated rice bran polysaccharide}

$0.5 \mathrm{~g}$ of rice bran polysaccharide was dissolved in $10 \mathrm{~mL}$ of distilled water, and the $\mathrm{pH}$ was adjusted to 9 with $\mathrm{NaOH}$ solution $(0.5 \mathrm{~mol} / \mathrm{L})$. At $30^{\circ} \mathrm{C}, 0.6 \mathrm{ml}$ of acetic anhydride (added multiple times) was added to the polysaccharide solution.After the addition of acetic anhydride has been completed, the reaction was carried out at a constant temperature for 2 hours.After the reaction, the $\mathrm{pH}$ of the reaction solution was adjusted to 7 with $1 \mathrm{~mol} / \mathrm{mL} \mathrm{HCl}$. The reaction solution was filled into a dialysis bag with a molecular weight of $3000 \mathrm{kDa}$.Distilled water was dialyzed for 48 hours. After the dialysate was concentrated, it was precipitated with 3 times the volume of ethanol (95\%) for 24 hours. The precipitate was freeze-dried to obtain acetylated rice bran polysaccharide (Ac-RBPs).

\subsubsection{Purification of polysaccharide}

The $(0.3 \mathrm{~g})$ crude polysaccharide was dissolved in $80 \mathrm{~mL}$ distilled water $\left(70{ }^{\circ} \mathrm{C}, 20\right.$ min). The crude polysaccharide was dissolved completely and centrifuged (4000 rpm) with a magnetic stirrer for $8 \mathrm{~min}$. The supernatant was separated by column chromatography on Sephadex G-100, and washed with distilled water. Sulphuric acid-phenol method was used to track and detect the change of sugar content during chromatography.

3.1.7 Discussion on the conditions of water extraction of crude rice bran polysaccharide

Consulting references, it is found that the main factors affecting the extraction rate $(\mathrm{E} \%)$ of rice bran polysaccharide extracted by water extraction are: reaction temperature (T), reaction time (Time) and solid-liquid ratio (Rs-1). 
In order to determine the optimal conditions for extracting rice bran polysaccharides by water extraction, an orthogonal test has been completed and the results are as follows:

(1) When the reaction temperature is $80^{\circ} \mathrm{C}$.

$\mathrm{T}=80^{\circ} \mathrm{C}$

\begin{tabular}{|c|l|l|l|}
\hline E\% Rs-I & $1: 5$ & $1: 10$ & $1: 15$ \\
\hline Time ( $\mathrm{h})$ & 1.32 & 1.53 & 1.64 \\
\hline 4 & 1.47 & 1.61 & 1.87 \\
\hline 5 & 1.51 & 1.88 & 1.96 \\
\hline 6 & & & \\
\hline
\end{tabular}

Table.3 Relationship between polysaccharide extraction rate and time and solid-liquid ratio $\left(80^{\circ} \mathrm{C}\right)$

(2) When the reaction temperature is $100^{\circ} \mathrm{C}$.

$$
\mathrm{T}=100^{\circ} \mathrm{C}
$$

\begin{tabular}{|c|c|c|c|}
\hline E\% Rs-I & $1: 5$ & $1: 10$ & $1: 15$ \\
\hline Time (h) & 1.69 & 1.82 & 1.90 \\
\hline 4 & 1.85 & 2.18 & 2.09 \\
\hline 5 & 1.88 & 2.12 & 2.19 \\
\hline 6 & & \\
\hline
\end{tabular}

Table.4 Relationship between polysaccharide extraction rate and time and solid-liquid ratio $\left(100^{\circ} \mathrm{C}\right)$

(3) When the reaction temperature is $120^{\circ} \mathrm{C}$. 


\begin{tabular}{|c|c|c|c|}
\hline E\% Rs-I & $1: 5$ & $1: 10$ & $1: 15$ \\
\cline { 1 - 2 } & 1.87 & 2.05 & 2.13 \\
\hline 5 & 1.85 & 1.98 & 2.03 \\
\hline 5 & 1.70 & 1.83 & 1.90 \\
\hline 6 & & \\
\hline
\end{tabular}

Table.4 Relationship between polysaccharide extraction rate and time and solid-liquid ratio $\left(120^{\circ} \mathrm{C}\right)$

It can be found from the Table.3 that when the temperature is $80^{\circ} \mathrm{C}$, the reaction time is $6 \mathrm{~h}$, the solid-liquid ratio $1: 15$ polysaccharide extraction rate is up to $1.96 \%$.It can be found from the Table. 4 that when the temperature is $100^{\circ} \mathrm{C}$, the reaction time is $6 \mathrm{~h}$, the solid-liquid ratio $1: 15$ polysaccharide extraction rate is up to $2.19 \%$.It can be found from the Table.5 that when the temperature is $120^{\circ} \mathrm{C}$, the reaction time is $4 \mathrm{~h}$, the solid-liquid ratio $1: 15$ polysaccharide extraction rate ias up to $2.13 \%$.

It can also be found from Table. 4 that when the temperature was at $100^{\circ} \mathrm{C}$ and the reaction time was $5 \mathrm{~h}$, the solid-liquid ratio $1: 10$ polysaccharide extraction rate is $2.18 \%$. While the reaction time was $6 \mathrm{~h}$, the solid-liquid ratio $1: 15$ polysaccharide extraction rate was $2.19 \%$, which was only slightly higher than the former. Therefore, from the perspective of saving energy, the water leaching conditions selected in this experiment were a temperature of $100^{\circ} \mathrm{C}$, a reaction time of $5 \mathrm{~h}$, and a solid-liquid ratio of $1: 10$.

3.1.8 Discussion on the conditions for precipitation of rice bran polysaccharides with ethanol

Because the concentration of ethanol and the volume ratio of ethanol to polysaccharide concentrate will affect the yield of rice bran polysaccharide, an orthogonal test was done. Concentration of ethanol $(80 \%, 95 \%, 100 \%)$ volume ratio of ethanol to concentrate $(2: 1,3: 1,4: 1)$ Because the concentrate is $200 \mathrm{ml}$, the volume of ethanol is $(400 \mathrm{ml}, 600 \mathrm{ml}, 800 \mathrm{ml})$.

In Table.5, ( $\mathrm{m}$ ) is the weight of the precipitated rice bran crude polysaccharide, (n) is the ethanol concentration, (V) is the volume of ethanol. 


\begin{tabular}{|c|c|l|l|}
\hline $\mathrm{m}_{(\mathrm{g})} \mathrm{V}(\mathrm{ml})$ & 200 & 600 & 800 \\
\hline $\mathrm{n}$ & 2.23 & 2.55 & 2.59 \\
\hline $90 \%$ & 2.65 & 3.18 & 3.19 \\
\hline $100 \%$ & 2.39 & 2.48 & 2.50 \\
\hline
\end{tabular}

Table.5 Relationship between the weight of crude polysaccharides from rice bran obtained and the ethanol concentration and ethanol volume

It can be found from Table.5 that when the ethanol concentration is $95 \%$ and the ethanol volume is $800 \mathrm{~mL}$, the yield of crude rice bran polysaccharide is $3.18 \mathrm{~g}$ at the maximum. When the ethanol concentration is $95 \%$ and the ethanol volume is $600 \mathrm{~mL}$, the yield of crude rice bran polysaccharide is slightly lower than the highest value. From the perspective of energy saving, $95 \%$ ethanol is used in this experiment, and the volume ratio of ethanol to polysaccharide concentrate is $3: 1$.

\subsection{Results}

\section{IR-detection}

Infrared spectrum detection of rice bran polysaccharide and its derivatives: mixing $3 \mathrm{mg}$ with $100 \mathrm{mg}$ of dried $\mathrm{KBr}$, grinding, tabletting, and scanning 4000-400 cm-1 wave band by Fourier transform infrared spectrometer.

\section{UV-detection}

Samples of rice bran polysaccharide and its derivatives were prepared into a $2 \mathrm{mg} / \mathrm{mL}$ solution, and the 200 600 $\mathrm{nm}$ band was scanned by an ultraviolet-visible spectrophotometer (UV-2550).

\section{${ }^{13} \mathrm{CNMR}$}

$\mathrm{D}_{2} \mathrm{O}$ was used to prepare a sample solution with a concentration of $40 \mathrm{~m} \mathrm{~g} / \mathrm{m} \mathrm{l}$, and the sample solution was analyzed and determined at room temperature by using a 300MHZ full digital nuclear magnetic resonance spectrometer (AVANCE II).

\subsubsection{IR detection}




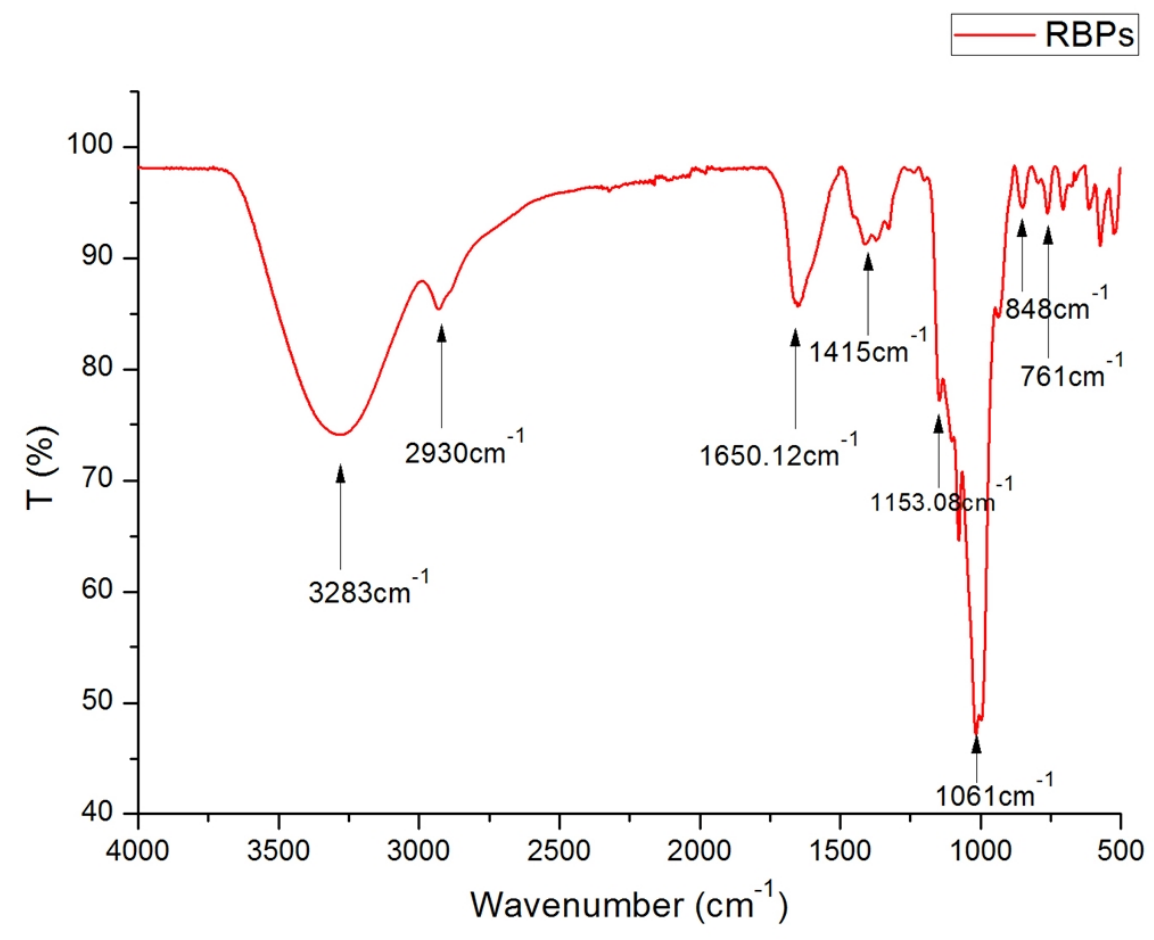

Fig.3 Infrared spectrum of rice bran polysaccharide

It can be found from Fig.3 that rice bran polysaccharide has a typical infrared absorption peak of polysaccharide. O-H tensile vibration at $3283 \mathrm{~cm}^{-1}, \mathrm{C}-\mathrm{H}$ tensile vibration at $2930 \mathrm{~cm}^{-1}$ and C-O-H tensile vibration at $1061 \mathrm{~cm}^{-1} .-\mathrm{CH}_{2}$ symmetric deformation vibration at $1415 \mathrm{~cm}^{-1},-\mathrm{CH}_{2}$ antisymmetric deformation vibration at $1153.08 \mathrm{~cm}^{-1}$, and $\mathrm{C}-\mathrm{O}$ stretching vibration at $1650.12 \mathrm{~cm}^{-1}$. The characteristic absorption peak of saccharide molecular vibration is in the region of $700-950 \mathrm{~cm}^{-1}$, and the measurement result has a strong absorption peak at $761 \mathrm{~cm}^{-1}$, which is presumed to be caused by the asymmetric contraction of $\mathrm{C}-\mathrm{O}-\mathrm{C}$ skeleton vibration of glucopyranose sugar ring. The absorption peak of $848 \mathrm{~cm}^{-1}$ is the characteristic of $\alpha$-epimer. Therefore, it can be inferred that $\alpha$-D-glucopyranose is the main component of polysaccharide. 


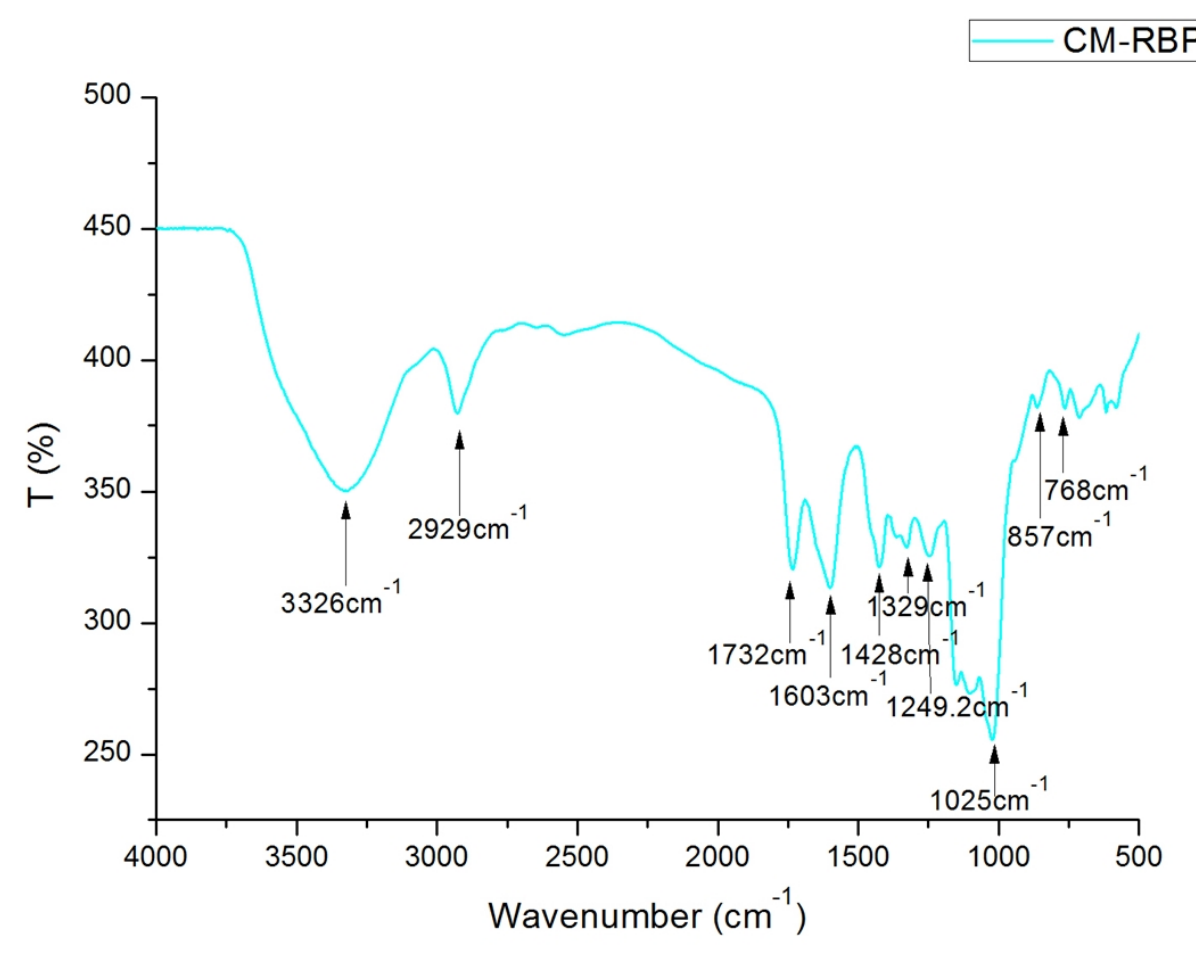

Fig.4 The Infrared spectrum of carboxymethylated rice bran polysaccharide

From Fig.4, we can see that the infrared spectrum of rice bran polysaccharide has no $1603 \mathrm{~cm}^{-1}$ and $1329 \mathrm{~cm}^{-1}$ (COO-stretch vibration), $1428 \mathrm{~cm}^{-1}$ (COO- The bending vibration of the $\mathrm{C}-\mathrm{H}$ group), these special infrared absorption peaks, meanwhile, they also have absorption peaks typical of rice bran polysaccharides, which can indicate that the experiment of carboxymethylation of rice bran polysaccharides was successful. 


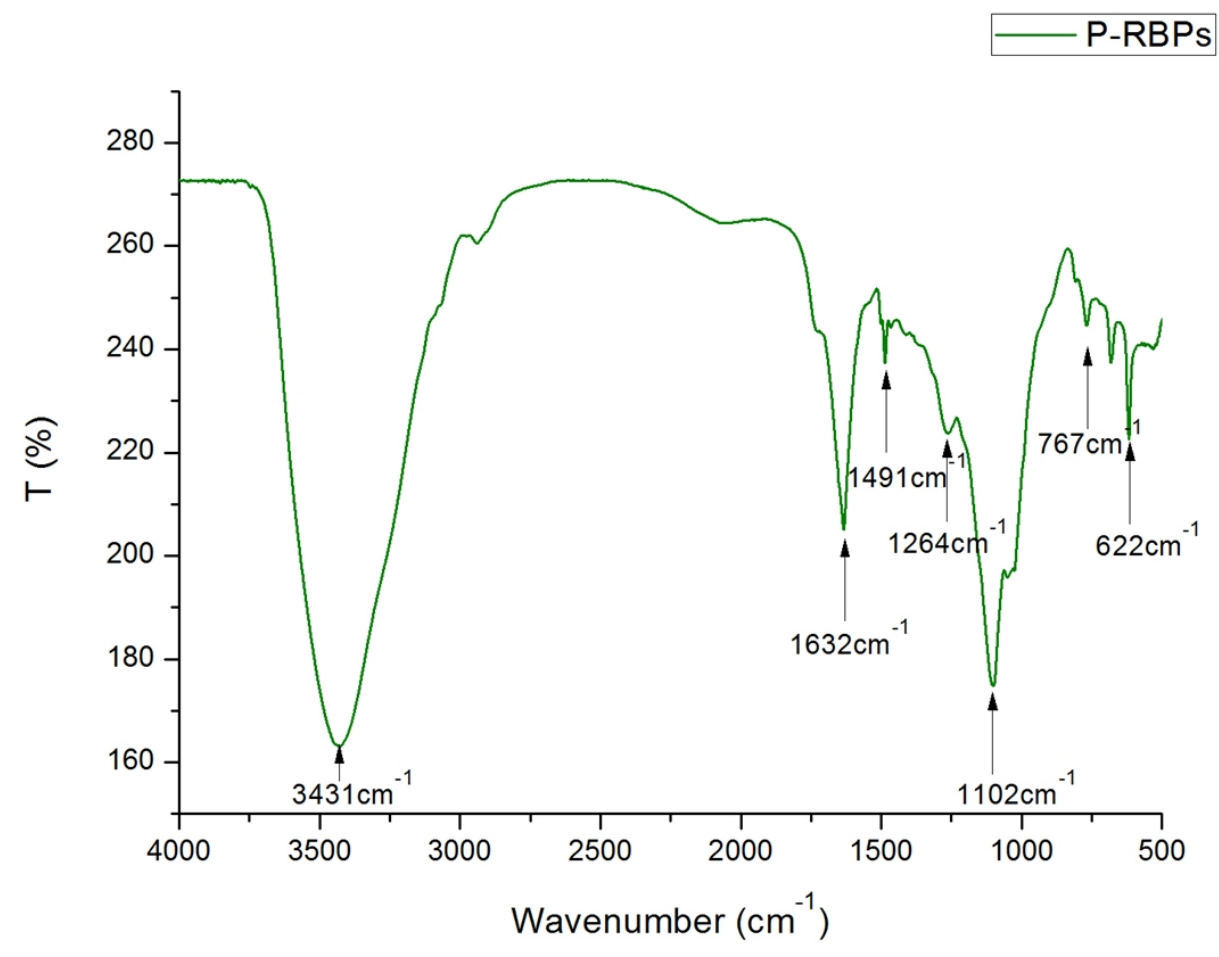

Fig. 5 Infrared spectrum of phosphorylated rice bran polysaccharide

As shown in Fig.5, the infrared spectrum of phosphorylated rice bran polysaccharide ranges from $3000 \mathrm{~cm}^{-1}$ to $3600 \mathrm{~cm}^{-1}$.At $2933 \mathrm{~cm}^{-1}$ is the $\mathrm{C}-\mathrm{H}$ stretching vibration absorption peak in methylene (-CH2-).The broad absorption peak is the characteristic peak of hydroxyl group on sugar ring, the asymmetric stretching peak of $\mathrm{C}-\mathrm{O}$ at $1632 \mathrm{~cm}^{-1}$, the angular vibration of $\mathrm{C}-\mathrm{H}$ at $1491 \mathrm{~cm}^{-1}$, the angular vibration of $\mathrm{O}-\mathrm{H}$ at $1102 \mathrm{~cm}^{-1}$, and a new weak absorption peak at $1264 \mathrm{~cm}^{-1}$, which is caused by $\mathrm{P}=\mathrm{O}$ in phosphate. Because the degree of substitution of phosphorylation is not high, and his absorption peak is relatively weak, we suspect that it is caused by hydrolysis of phosphorus oxychloride, which can preliminarily indicate that phosphate is likely to be successfully introduced. 


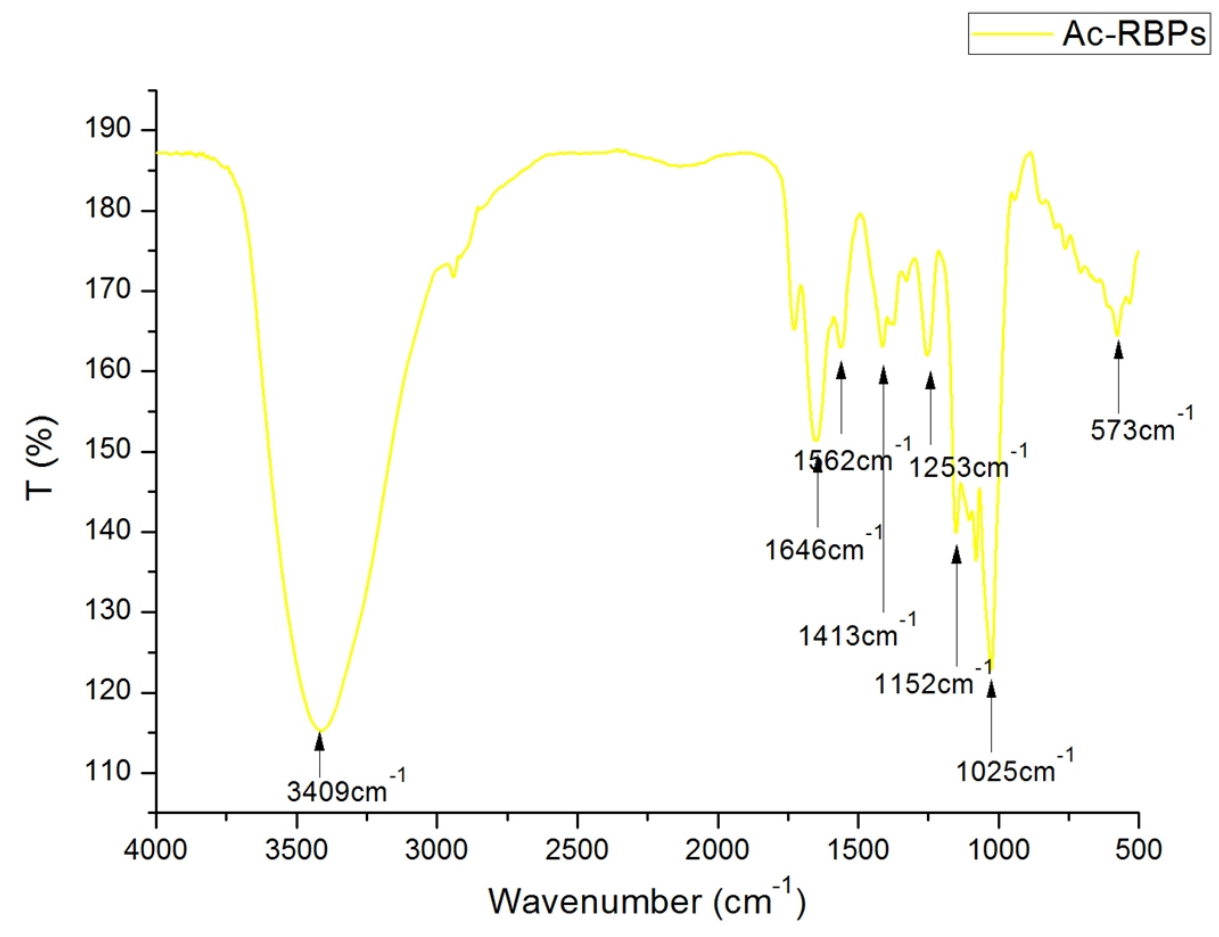

Fig. 6 Infrared spectrum of acetylated rice bran polysaccharide

At $3409 \mathrm{~cm}^{-1}$ is the stretching vibration peak of the intramolecular or intermolecular hydrogen bond $\mathrm{O}-\mathrm{H}$ of the polysaccharide.Ac-RBPs obtained after acetylation modification showed a new absorption peak at $1727 \mathrm{~cm}^{-1}$ which was the contraction vibration peak of the ester group $\mathrm{C}=\mathrm{O}$ double bond, and at the same time, a weaker ester group C-O contraction vibration peak appeared at $1253 \mathrm{~cm}^{-1}$. It shows that the acetyl group has been successfully introduced into the rice bran polysaccha. 


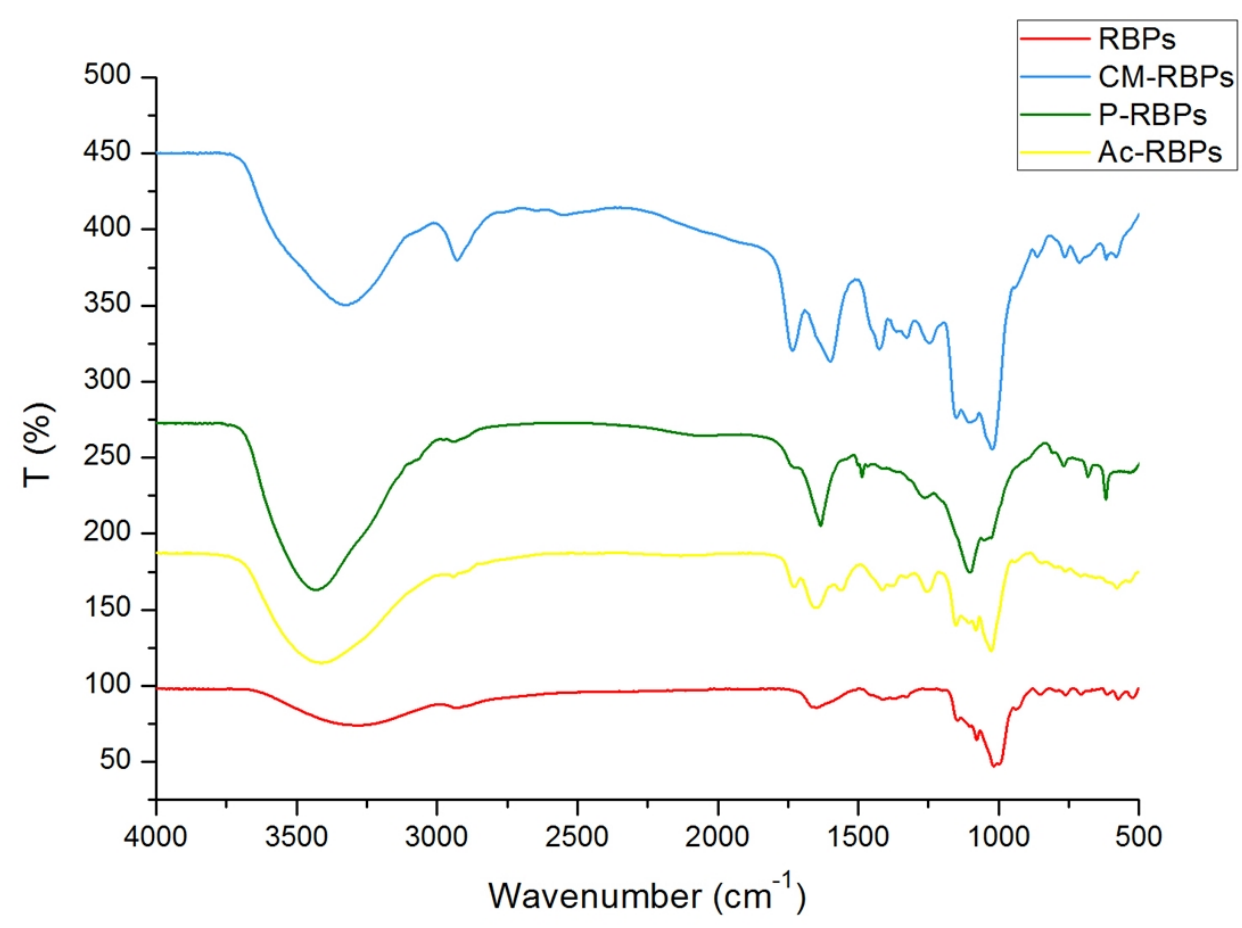

Fig. 7 Comparison of infrared spectra of rice bran polysaccharides and several derivatives

\subsubsection{UV detection}

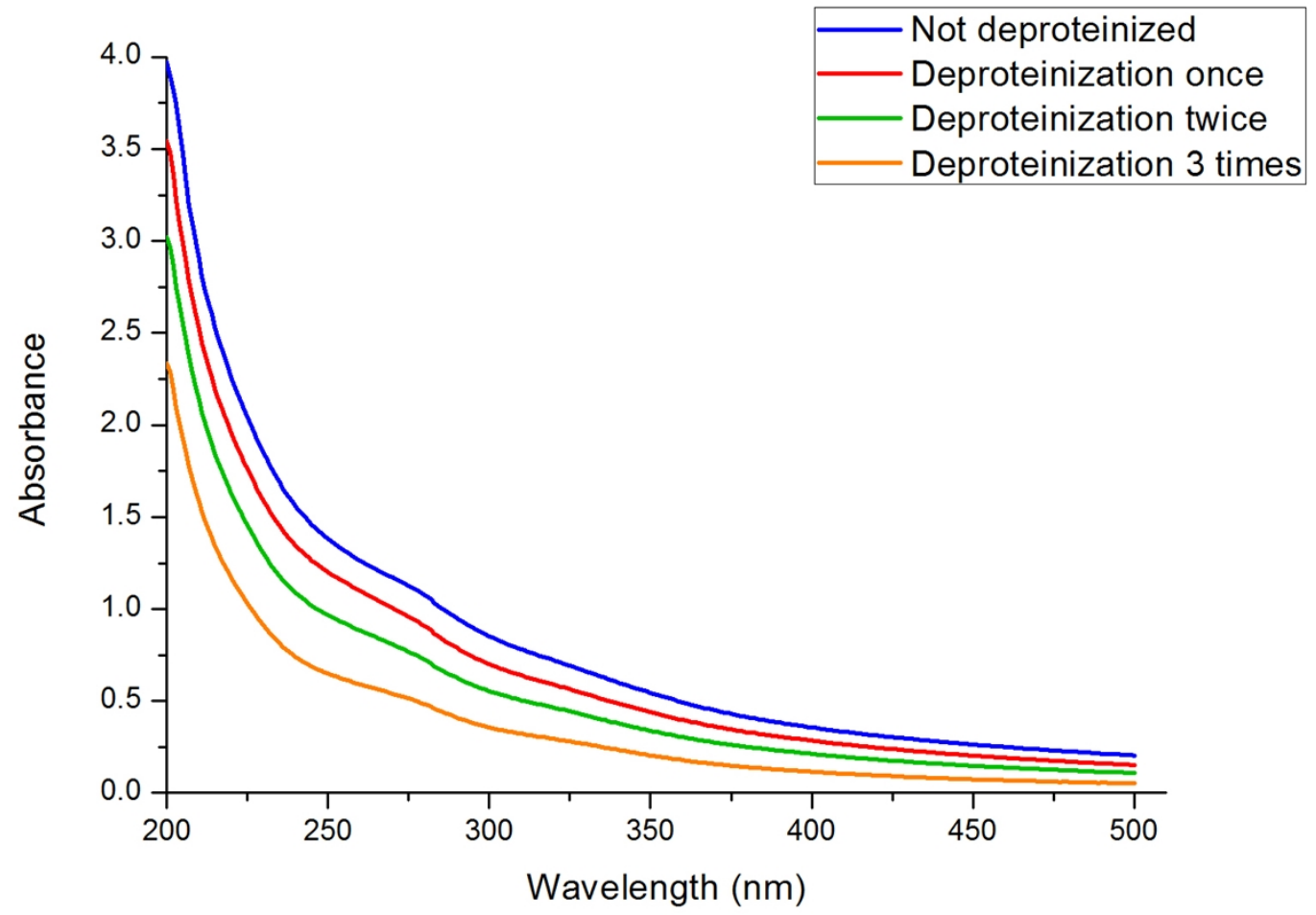

Fig.8 UV spectrum of rice bran polysaccharide 
Rice bran polysaccharide showed a weak absorption peak at 260-280 nm, and the protein had a characteristic absorption peak around $260 \mathrm{~nm}$. The benzene ring of the tyrosine and tryptophan residues in the protein contained conjugated double bonds, so the protein solution was. There is an absorption ultraviolet absorption peak at $280 \mathrm{~nm}$. When the sample contains nucleic acids such as purines and pyrimidines that absorb ultraviolet light, there will be greater interference when measuring the protein content at $280 \mathrm{~nm}$. It indicates that the rice bran polysaccharide may contain a small amount of tyrosine, tryptophan and nucleic acid.[29]

The rice bran polysaccharide has been deproteinized. According to Fig. 8, it can be seen that the absorbance of rice bran polysaccharide without deproteinization treatment is highest at $260 \mathrm{~nm}$ and $280 \mathrm{~nm}$, while the absorbance at $260 \mathrm{~nm}$ and $280 \mathrm{~nm}$ decreases with the increase of the number of deproteinization. After the three deproteinization treatments, the absorbance decreased significantly.

\subsection{3 ${ }^{13} \mathrm{C}$ NMR}

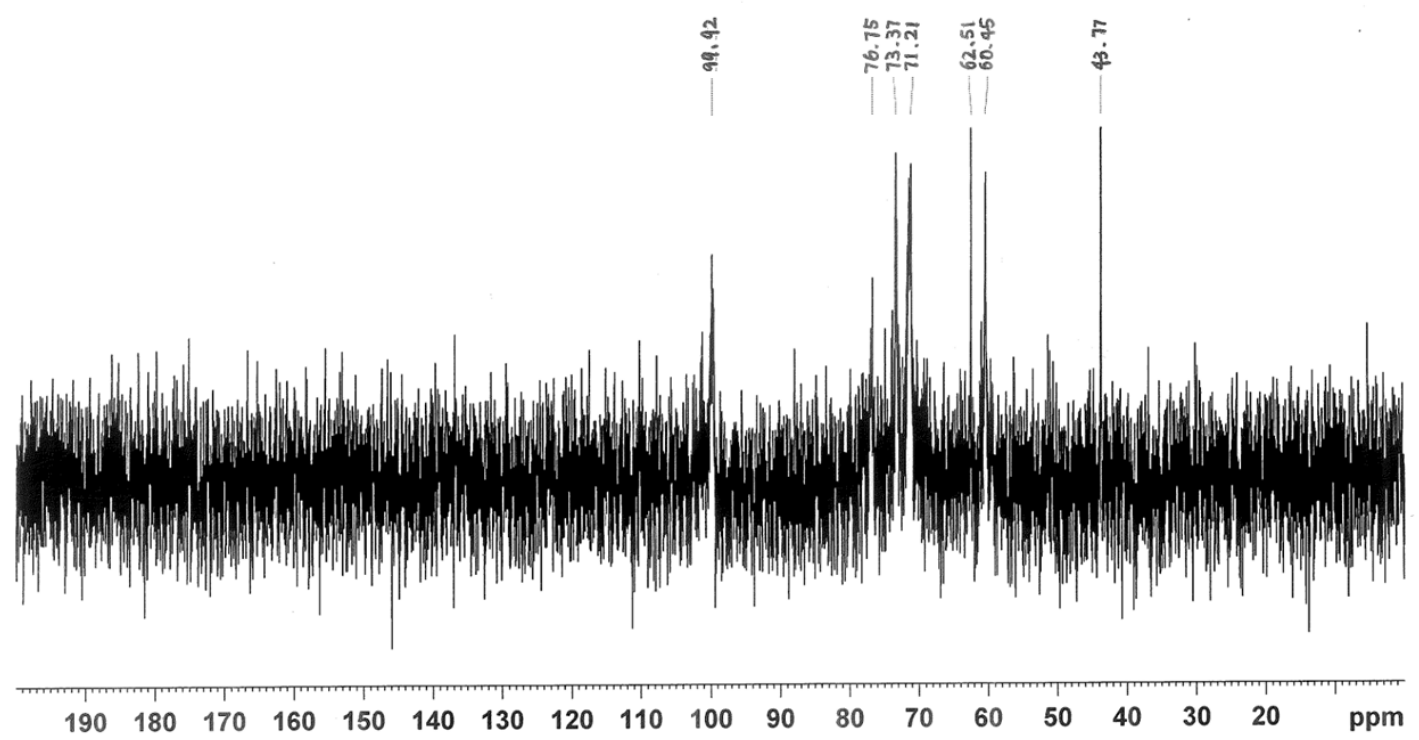

Fig.9 ${ }^{13} \mathrm{C}$ NMR of rice bran polysaccharide

At present, we want to find out the connection position between monosaccharide, and the commonly used method is nuclear magnetic resonance detection. A sample of $50 \mathrm{mg}$ rice bran polysaccharide was dissolved in $0.5 \mathrm{~mL} \mathrm{D}_{2} \mathrm{O}$.

After loading the sample, we tested it at $20^{\circ} \mathrm{C}$ at room temperature. After 3 hours, we got the results as shown in Fig.9. We can infer that the connecting end is $\alpha$-Dglycosidic bond structure; The attribution of the peaks is as follows:62.51ppm(C-6);71.21ppm(C-5);73.37ppm(C-2);76.75ppm(C-4);78.75ppm(C$3) ; 99.92 \mathrm{ppm}(\mathrm{C}-1)$. The above indicates that rice bran polysaccharide (RBPs) has two 
glycosidic bond forms of $\alpha-1,4$ and $\alpha-1,6$, of which $\alpha-1,4$ has a large structural content.
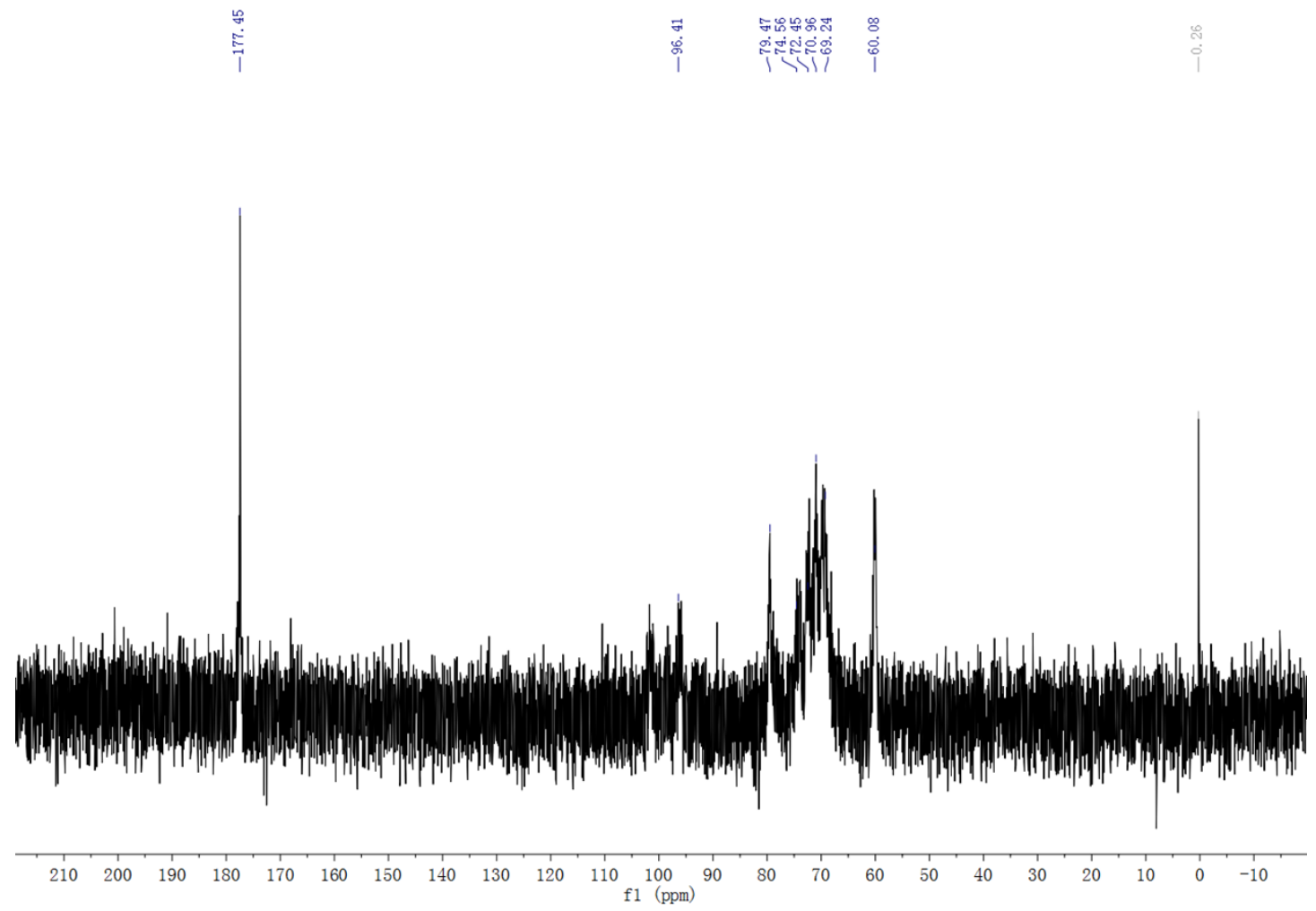

Fig.10 13C NMR of carboxymethylated rice bran polysaccharide

At present, to find out the connection position between monosaccharides, the common method is nuclear magnetic resonance detection. A sample of $50 \mathrm{mg}$

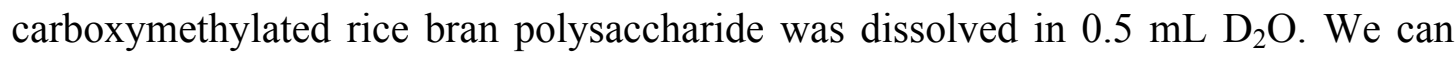
infer that the connecting end is $\alpha$-D- glycosidic bond structure; The attribution of the peaks is as follows :60.08ppm(C-6);69.24ppm(C-5);2.45ppm(C-2);74.55ppm(C-4); $79.47 \mathrm{ppm}(\mathrm{C}-3) ; 96.41 \mathrm{ppm}(\mathrm{C}-1)$; The new chemical shifts at $177.45 \mathrm{ppm}$ could be attributed to the (C-O) of carboxymethyl group. The above indicates that rice bran polysaccharide (RBPs) has two glycosidic bond forms of $\alpha-1,4$ and $\alpha-1,6$, of which $\alpha-1$, 4 has a large structural content. 


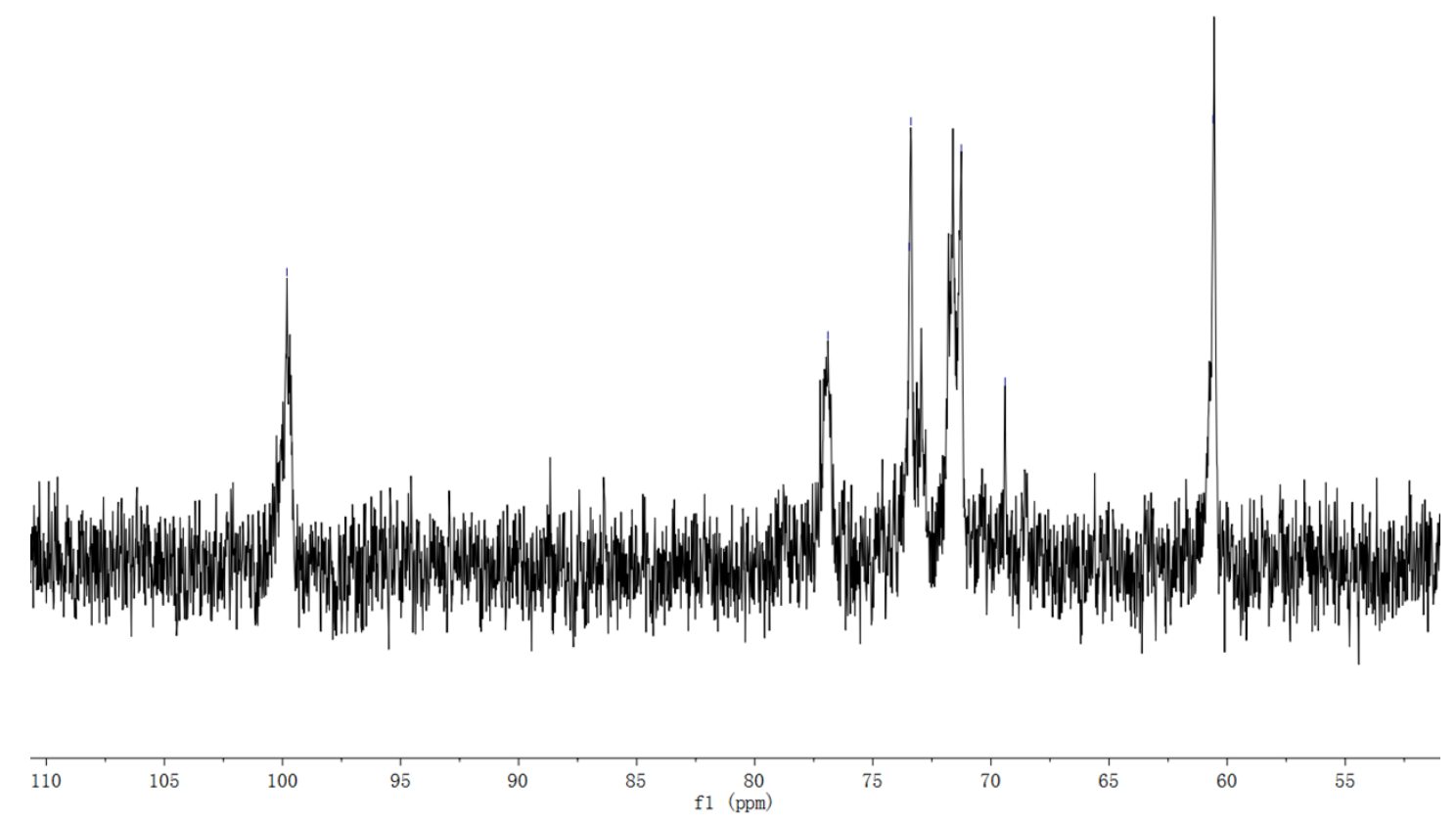

Fig.11 ${ }^{13} \mathrm{C}$ NMR of phosphorylated rice bran polysaccharide

A sample of $50 \mathrm{mg}$ phosphorylated rice bran polysaccharide was dissolved in 0.5 $\mathrm{mL} \mathrm{D}_{2} \mathrm{O}$.After loading the sample, we tested it at $20^{\circ} \mathrm{C}$ at room temperature. After 3 hours, we got the results as shown in Fig.11.

99.81ppm(C-1);73.39ppm73.46ppm(C-2);68.56ppm(C-4);76.90ppm(C-5);60.59 $\operatorname{ppm}(\mathrm{C}-6) 71.25 \mathrm{ppm} 68.4 \mathrm{ppm}(\mathrm{C}-7)$; 


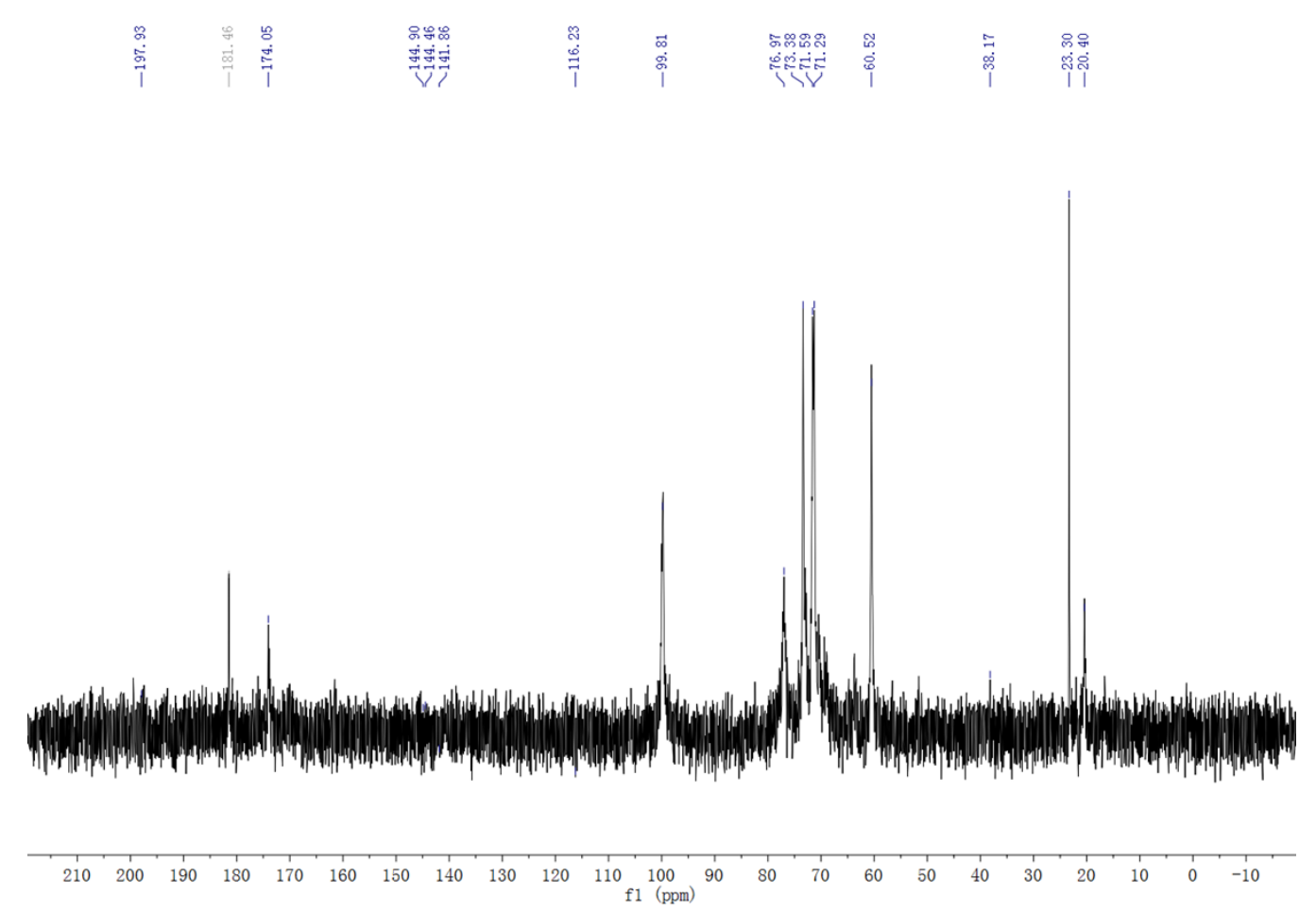

Fig.12 ${ }^{13} \mathrm{C}$ NMR of acetylated rice bran polysaccharide

A sample of $50 \mathrm{mg}$ acetylated rice bran polysaccharide was dissolved in $0.5 \mathrm{~mL}$ $\mathrm{D}_{2} \mathrm{O}$.After loading the sample, we tested it at $20^{\circ} \mathrm{C}$ at room temperature. After 3 hours, we got the results as shown in Fig.12.

99.81ppm(C-1);60.52ppm(C-6);71.29,71.59ppm(C-3);73.38ppm(C-2);76.97ppm (C-5);174.05ppm(C-8);181.46ppm(C-9)

\section{Various antioxidant activities}

\subsection{Determination of hydroxyl radical scavenging ability}

Reaction mechanism: $\mathrm{Fe}^{2+}+\mathrm{H}_{2} \mathrm{O}_{2}==\cdot \mathrm{OH}+\mathrm{OH}{ }^{-}+\mathrm{Fe}^{3+}$, as shown in Fig.13.

Salicylic acid can react with it to generate 2,3-dihydroxybenzoic acid and 2,5-dihydroxybenzoic acid. These two isomers have UV absorption at 510nm. The stronger the absorption, it indicates that the salicylic acid is bound. The more hydroxyl radicals you have. Vc or polysaccharide can also scavenge hydroxyl radicals. If the same amount of salicylic acid is added, the same hydroxyl radicals are generated. The ability of polysaccharides to scavenge hydroxyl radicals is determined by measuring the difference in absorption at $510 \mathrm{~nm}$ after adding polysaccharides. As shown in Fig.14. 
Fig.13 Reaction principle of hydroxyl radical with salicylic acid
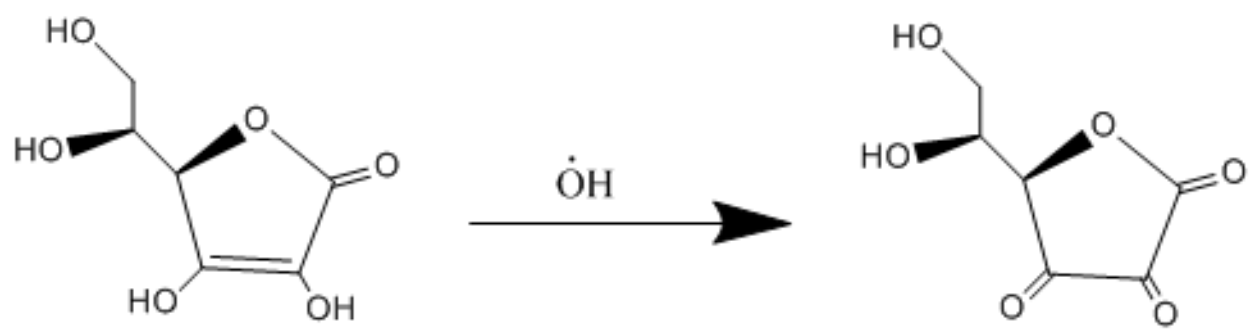

Fig.14 Mechanism of $\mathrm{V}_{\mathrm{c}}$ scavenging hydroxyl radicals

Specific experimental steps: The sample solution $(1 \mathrm{~mL})$ of rice bran polysaccharide and its derivatives with concentrations of $0.1,0.2,0.4,0.8,1.6,3.2$ $\mathrm{mg} / \mathrm{mL}$ was added to the test tube(distilled water was used as a control). $1 \mathrm{~mL}$ $9 \times 10^{-3} \mathrm{~mol} / \mathrm{L} \mathrm{FeSO}_{4}, 1 \mathrm{~mL} 9 \times 10^{-3} \mathrm{~mol} / \mathrm{L}$ salicylic acid-ethanol solution $(70 \%$ aqueous solution) were added to the test tube.After being thoroughly mixed, $9 \times 10^{-3} \mathrm{~mol} / \mathrm{L}$ $\mathrm{H}_{2} \mathrm{O}_{2}$ solution $(1 \mathrm{~mL})$ was added to the test tube. They were all placed in a constant temperature oil bath at $37^{\circ} \mathrm{C}$ and reacted for 30 minutes.After the solution was cooled to room temperature, the UV absorbance of the solution was measured at $510 \mathrm{~nm}$ and recorded as As. Vc was used as a positive control group, and the test was repeated three times.

The hydroxyl radical scavenging rate $\mathrm{E}$ is calculated according to the following formula:

$E=\left[A_{b^{-}}\left(\mathbf{A}_{s^{-}}-\mathbf{A}_{c}\right)\right] / \mathbf{A}_{c} \times \mathbf{1 0 0 \%}$

$A_{b}$ : Substitute the absorbance of polysaccharide sample with distilled water

$A_{s}$ : Absorbance after adding the sample solution

\section{$A_{c}$ : Absorbance of rice bran polysaccharide or its derivative solution itself}




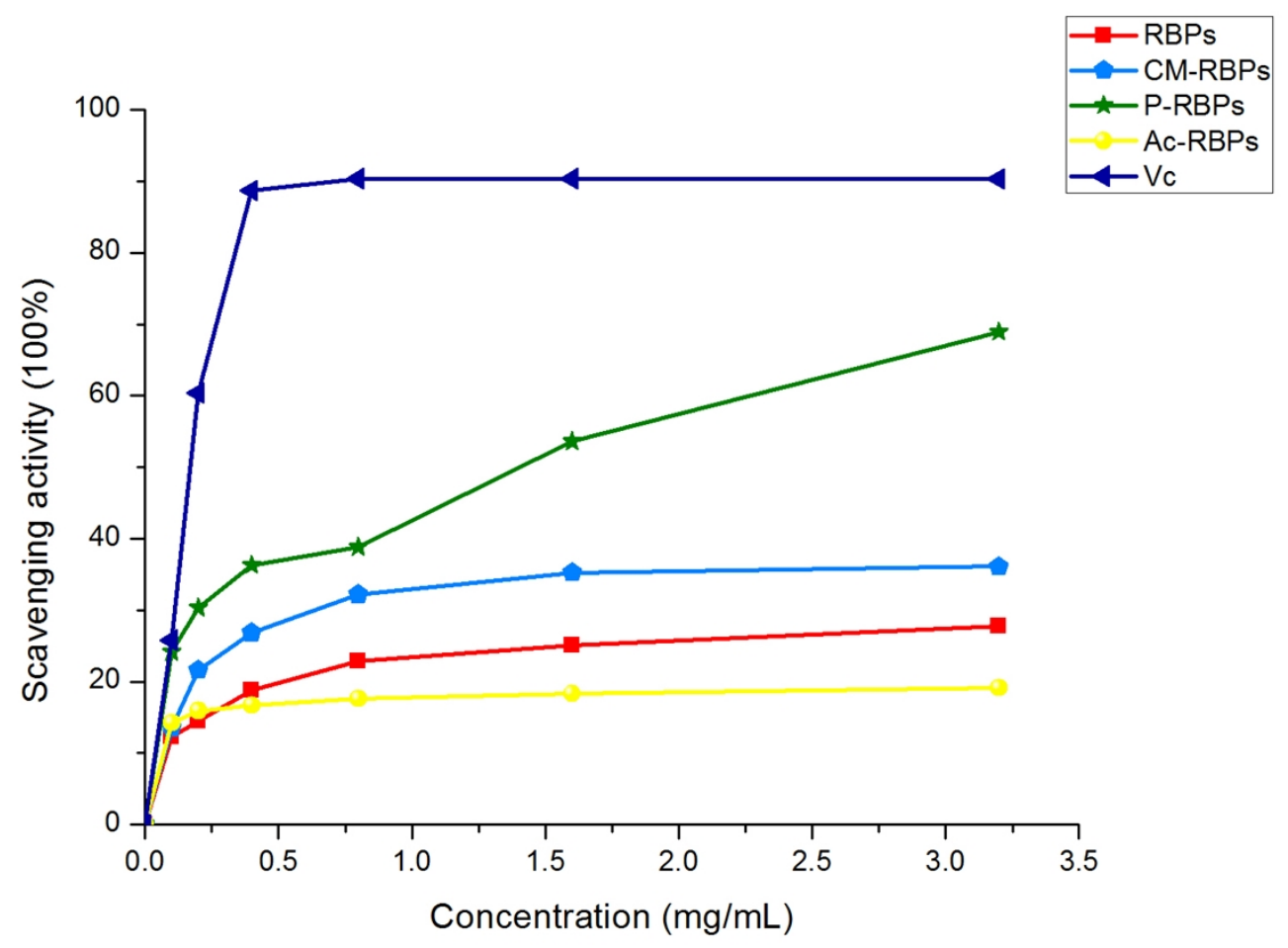

Fig.15 Results of hydroxyl radical ion scavenging ability

Vc was used as a positive control group of rice bran polysaccharides and their derivatives to study the ability of rice bran polysaccharides and their derivatives to scavenge hydroxyl radical ions.As shown in Fig.15,rice bran polysaccharides and several derivatives at a concentration of $0.1-3.2 \mathrm{mg} / \mathrm{mL}$ showed the ability to scavenge $\cdot \mathrm{OH}$ with increasing concentration. Among them, the ability of low-concentration Ac-RBPs $(0.1-0.2 \mathrm{mg} / \mathrm{mL})$ to remove $\cdot \mathrm{OH}$ is higher than that of the same concentration of RBPs, but with the concentration increases, the ability of Ac-RBPs to remove $\cdot \mathrm{OH}$ is significantly lower than RBPs. However, both P-RBPs and CM-RBPs significantly improved the ability to remove $\cdot \mathrm{OH}$. Among them, the P-RBPs at a concentration of $3.2 \mathrm{mg} / \mathrm{mL}$ showed the best ability to remove $\cdot \mathrm{OH}$, with a removal rate of $68.9 \%$. Compared with the same concentration of rice bran polysaccharide, the scavenging rate of hydroxyl radicals $(27.8 \%)$ increased by $41.1 \%$.But they are still lower than $\mathrm{Vc}$ 's ability to remove $\bullet \mathrm{OH}$.

\subsection{Superoxide anion scavenging ability}


In an environment with a $\mathrm{pH}$ value greater than 7 , pyrogallic acid can reflect its strong reducing ability and undergo an auto-oxidation reaction, simultaneously generating superoxide anion radicals $\left(\mathrm{O}_{2}^{-\bullet}\right)$ and colored intermediates. The reaction mechanism is shown in Fig.16 The intermediate product has a characteristic ultraviolet absorption peak at $\lambda=320 \mathrm{~nm}$. In the early stage of the reaction, the total amount of intermediate products is positively correlated with time. When added with scavengers such as $\mathrm{Vc}$ to remove superoxide anions, it can react with $\mathrm{O}_{2}{ }^{-\bullet}$, which can effectively prevent the continued formation and accumulation of intermediate products, resulting in a weakened UV absorption of the solution at $\lambda=320 \mathrm{~nm}$. Therefore, the ability of rice bran polysaccharide to remove $\mathrm{O}_{2}^{-\bullet}$ can be judged by measuring the value there.<smiles>CC(C)C(=O)O</smiles><smiles>O=C1C(=O)C2C(=O)C(O)=C(CCO)C=CC2C=C1O</smiles>

Fig.16 Pyrogallol auto-oxidation process

Specific experimental steps: The concentration of $0.1,0.2,0.4,0.8,1.6,3.2$ $\mathrm{mg} / \mathrm{mL}$ rice bran polysaccharide and its derivative solutions $(0.2 \mathrm{~mL})$ were added to different test tubes (the control group was replaced with distilled water). $3 \mathrm{~mL}$ of $0.05 \mathrm{~mol} / \mathrm{L}, \mathrm{pH} 8.2 \mathrm{Tris} \bullet \mathrm{HCl}$ buffer solution was added to the test tube. They were all placed in a constant temperature oil bath with a temperature of $25^{\circ} \mathrm{C}$, and holding 10 minutes. The preheated $30 \mathrm{mmol} / \mathrm{L}$ pyrogallic acid solution $(12 \mathrm{uL})$ was added to the test tube, and reacted accurately for 4 minutes. The reaction has been terminated with 
$0.5 \mathrm{~mL}$ concentrated hydrochloric acid. The absorbance at $320 \mathrm{~nm}$ was measured.And use an equal volume of $\mathrm{pH} 8.2$ Tris $\bullet \mathrm{HCl}$ buffer solution as a blank control group , and $\mathrm{Vc}$ as a positive control group, the test was repeated three times.

The hydroxyl radical scavenging rate $\mathrm{E}$ is calculated according to the following formula:

$E=\left(A_{c}-A_{s}\right) /\left(A_{c}-A_{b}\right) \times 100 \%$

$A_{b}$ : Tris $\bullet$ HCl buffer absorbance

$A_{s}$ : Absorbance after adding the sample solution

$A_{c}:$ Tris $\bullet$ HCl buffer solution + absorbance of pyrogallic acid

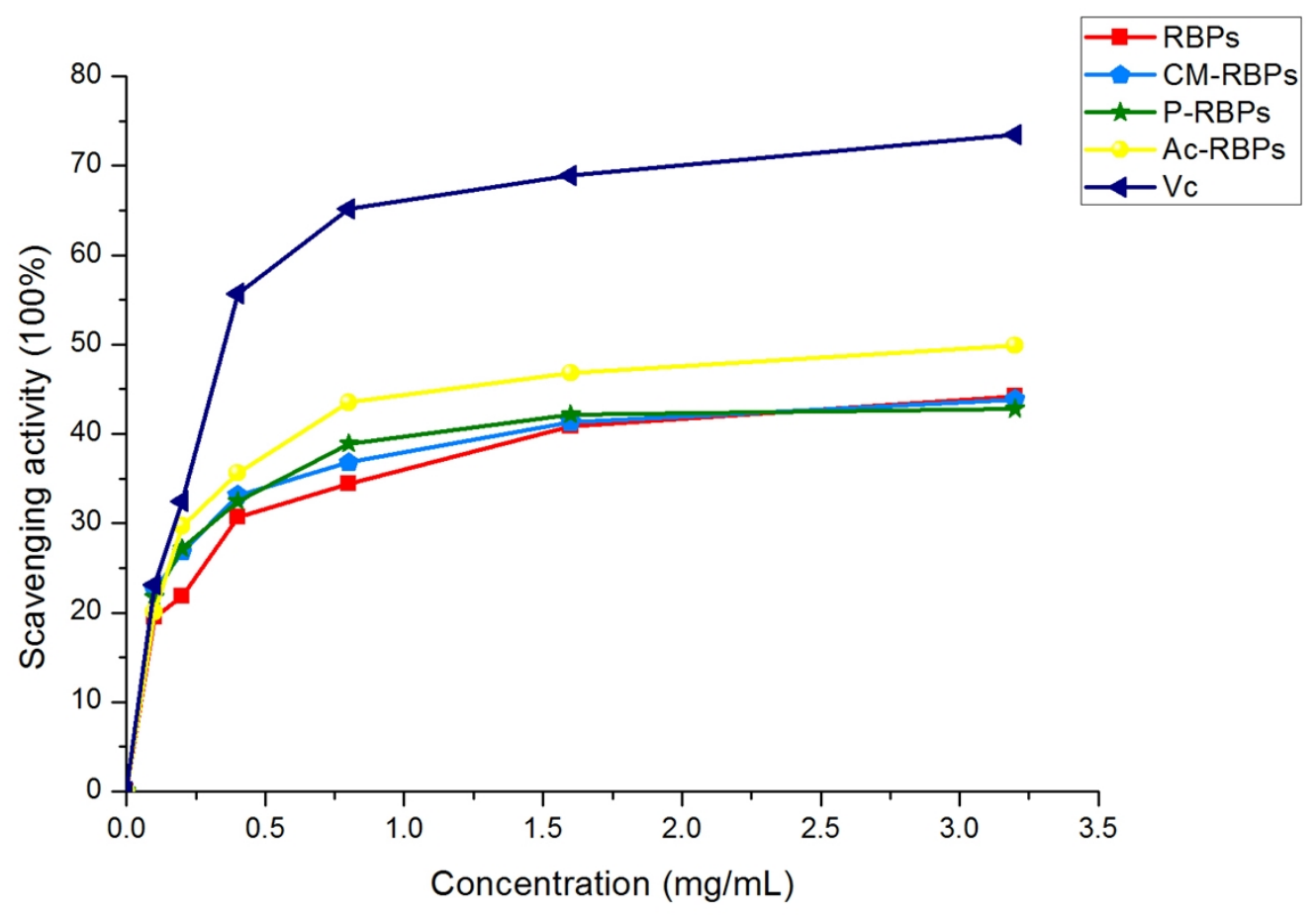

Fig.17 Results of superoxide anion scavenging ability

Vc was used as a positive control group of rice bran polysaccharide and its derivative solution to study the ability of rice bran polysaccharide and its derivatives to remove superoxide anions. From the Fig.17, it can be found that Ac-RBPs shows relatively good ability to remove superoxide anions. At a concentration of $3.2 \mathrm{mg} / \mathrm{mL}$, the superoxide anion scavenging rate of Ac-RBPs reached 49.9\%.That scavenging rate of rice bran polysaccharide at low concentration $(0.1-0.8 \mathrm{mg} / \mathrm{mL})$ is lower than that of the other two derivatives.However, the scavenging rate of rice bran polysaccharides at high concentrations $(1.6-3.2 \mathrm{mg} / \mathrm{mL})$ to superoxide anions is even slightly higher than that of the other two derivatives.However, the scavenging ability of superoxide anion for all sample groups is still less than Vc. 


\subsection{Reduction ability}

Analysis of reducing power measures the electron-donating ability of antioxidants using the potassium ferricyanide reduction method [30].The reducing activities were usually related to the development of reductones, which terminate free radical chain reactions by donating a hydrogen atom[31]. The Fig.18 reflects the principle of detecting the reducing ability of polysaccharides.

$$
\begin{aligned}
& \mathrm{Fe}^{3+} \stackrel{\text { reducing agent }}{\longrightarrow} \mathrm{Fe}^{2+} \\
& 3 \mathrm{Fe}^{2+}+2\left[\mathrm{Fe}(\mathrm{CN})_{6}\right]^{3-}=\mathrm{Fe}_{3}\left[\mathrm{Fe}(\mathrm{CN})_{6}\right]_{2} \downarrow
\end{aligned}
$$

Fig.18 Reaction mechanism

The samples with different concentrations $(0.1,0.2,0.4,0.8,1.6,3.2 \mathrm{mg} / \mathrm{mL}, 1.0 \mathrm{~mL})$ were mixed with $2.5 \mathrm{~mL}$ of $\mathrm{PBS}(\mathrm{pH} 6.6)$ and $2.5 \mathrm{~mL}$ of potassium ferricyanide $(1 \%)$. The mixture was incubated for $30 \mathrm{~min}$ at $50{ }^{\circ} \mathrm{C}$. The reaction was termi-nated by TCA solution $(10 \%)$. Then, the solution $(2 \mathrm{~mL})$ was mixed with distilled water $(2 \mathrm{~mL})$ and ferric chloride $(0.1 \%, 0.4 \mathrm{~mL})$.Measure its $\mathrm{UV}$ absorbance at $700 \mathrm{~nm}$, the higher the absorbance, the higher the reduction ability. Vc was used as a control group.

The absorbance: $\mathrm{A}=\mathbf{A} \mathbf{i}-\mathbf{A}_{\mathbf{0}}$. Ai:The absorbance of sample. $A_{0}$ : The absorbance of control. 


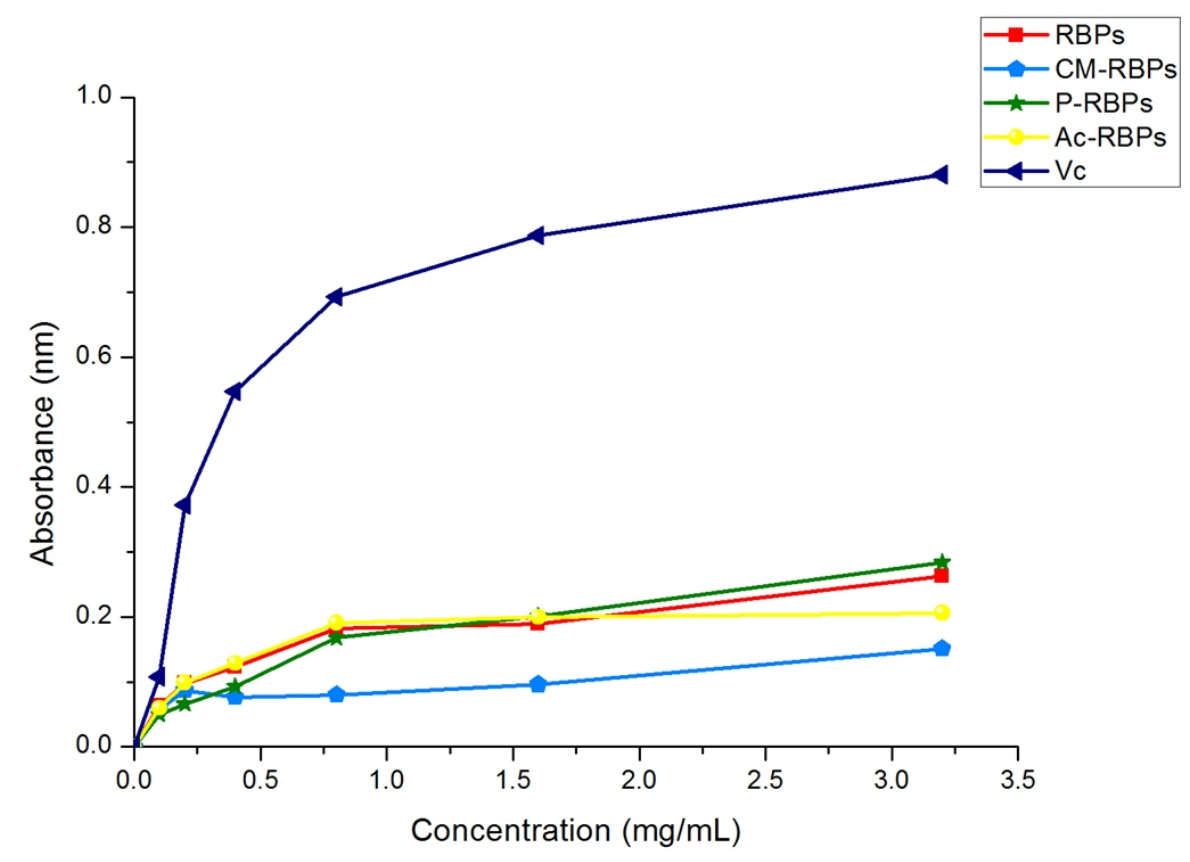

Fig.19 Results of reduction ability

It can be seen from Fig. 19 that the reducing ability of several samples increases with the increase of concentration. The reducing ability of rice bran polysaccharides is significantly weakened after carboxymethylation and acetylation. Compared with the same concentration of rice bran polysaccharides, there is almost no difference in reducing ability of phosphorylated rice bran polysaccharides. Several derivatizations are not helpful in improving the reducing ability of rice bran polysaccharides. The reducing ability of rice bran polysaccharide and its derivatives is much weaker than that of $\mathrm{Vc}$.

\subsection{Determination of anti-lipid peroxidation ability}

$0.1 \mathrm{~g}$ of soy lecithin has been weighed. Soy lecithin has been mixed with $\mathrm{pH}=$ 7.4 PBS (100 mL). The rice bran polysaccharide solution or its derivative solution (4 $\mathrm{mL}$ ) has been added to each test tube at a concentration of $0.1,0.2,0.8,0.4,1.6,3.2$ $\mathrm{mg} / \mathrm{mL}$. And soy lecithin solution $(3.6 \mathrm{~mL}), 10 \mathrm{mmol} / \mathrm{L} \mathrm{FeSO}_{4}(0.4 \mathrm{~mL})$ solution, $10 \mathrm{mmol} / \mathrm{L} \mathrm{Vc}$ solution $(0.4 \mathrm{~mL})$, have been added to the test tube.Incubate at $37^{\circ} \mathrm{C}$ for $60 \mathrm{~min}$ and cool to $25^{\circ} \mathrm{C}$. Add $1.0 \mathrm{~mL}$ of trichloroacetic acid (TCA, 20\%, w/v) and $1.0 \mathrm{~mL}$ of thiobarbituric acid (TBA, $0.8 \%, \mathrm{w} / \mathrm{v}$ ) successively, and heat the mixture at $100^{\circ} \mathrm{C}$ for 15 minutes. Centrifuge at $3000 \mathrm{rpm}$ Collect the supernatant of the sample after 15 minutes. The discoloration was measured at $532 \mathrm{~nm}$.

Inhibitionrate $(\mathbf{E} \%)=(\mathbf{A i}-\mathbf{A}) /\left(\mathbf{A}_{\mathbf{i}}-\mathbf{A}_{\mathbf{0}}\right) \times \mathbf{1 0 0} \%$

$A_{0}$ :The absorbance value of Tris-HCl buffer.

$\mathrm{A}_{\mathrm{i}}$ : The absorbance value of Tris-HCl buffer solution and pyrogallol solution.

A: The absorbance of sample solution. 


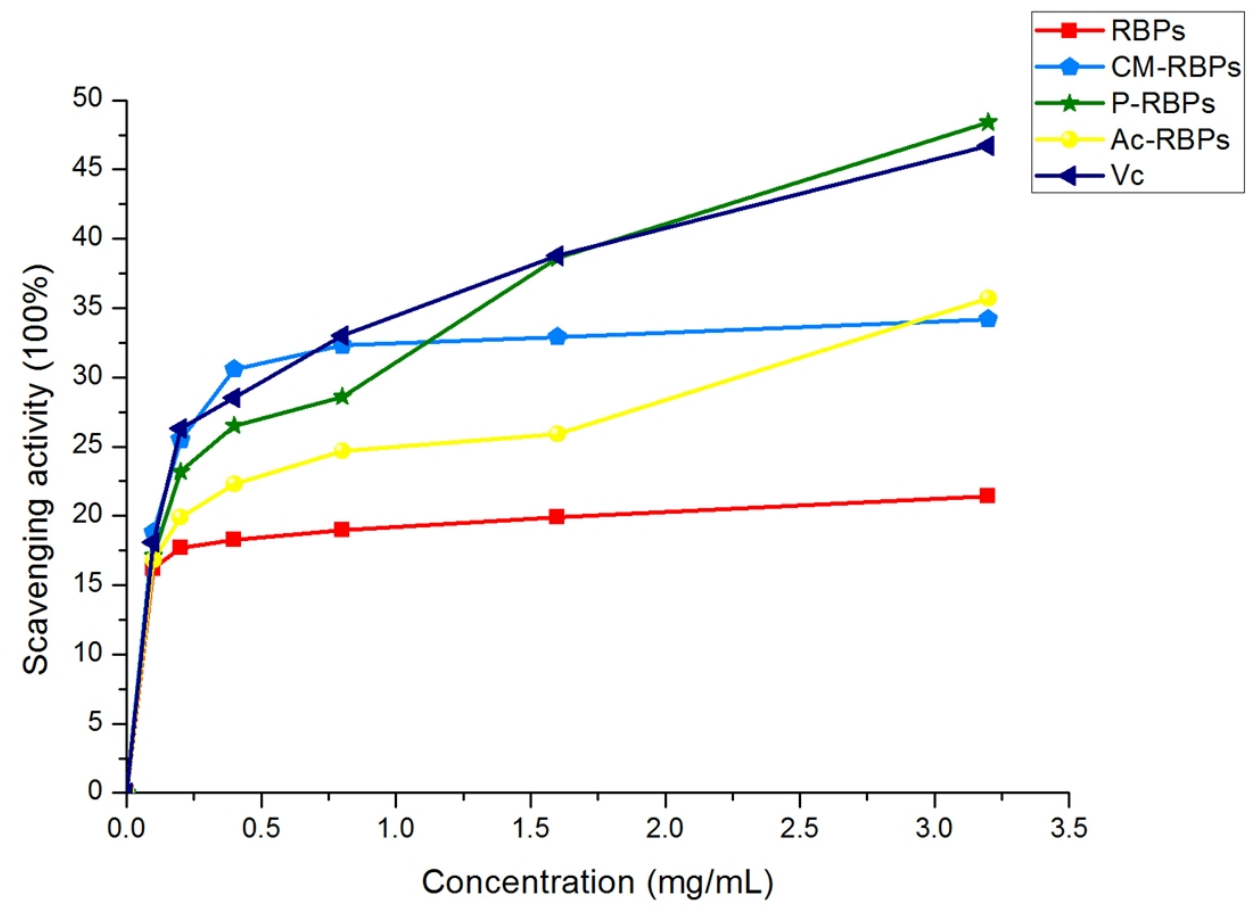

Fig.20 Results of anti-lipid peroxidation

According to Fig. 20, the anti-lipid peroxidation ability of carboxymethylated rice bran polysaccharide, phosphorylated rice bran polysaccharide, and acetylated rice bran polysaccharide all exceeded the ability of underivatized rice bran polysaccharide. Of particular concern is the anti-lipid peroxidation ability of high concentration $(3.2 \mathrm{mg} / \mathrm{mL})$ phosphorylated rice bran polysaccharide even surpasses that of the same concentration of $\mathrm{Vc}$.

\section{Results and discussion}

In addition to further proof of its polysaccharide composition, infrared characteristic absorption spectra at 761,848 , and $933 \mathrm{~cm}-1$ were also found in the fingerprint area. These results can prove that the sample was composed of $\alpha$-D-glucopyranose. In addition to further proof of the infrared results, a carbon spectrum nuclear magnetic resonance method was used to find the glycosidic bonds between the glycan rings: the connection mode of $\alpha-1,4$ and $\alpha-1,6$ glycosidic bonds. And found that the anti-lipid peroxidation ability of phosphorylated rice bran polysaccharide is better than Vc. In the next work, we are also going to carry out carboxymethyl phosphorylation, sulfation and carboxymethyl sulfation of rice bran polysaccharides and further study the antioxidant activity of rice bran polysaccharide derivatives. In order to prepare derivatives with better antioxidant activity.

\section{References}

[1] Liu, W., Zhang, J.S., Wang X.L., et al., 2000. Deep processing and comprehensive utilization of rice bran[J]. Present Modernized Agriculture 3(11), 19-20.

[2] Luhbs, 1991. Rice Utilization[M]. New York Springer, 313-362 . 
[3] Tatsunoriy, Takumat,2009. Rice water- soluble polysaccharide fractions with anticomplementary[J]. Activity Cereal Chemistry. 80 (11), 5-8.

[4] Zhao, X.Q., Wang, J.H., Yang, X.F., et al., 2009. Antioxidant properties of polysaccharide fractions with different molecular mass extracted with hot-water from rice b ran $[\mathrm{J}]$. Carbohydrate Polymers. 78 (3), 570 - 575.

[5] Li, H.Y., Fan, J., 2005.Study on Water Extraction and Alcohol Precipitation of Jujube Polysaccharide Study [J]. Ningxia Engineering Technology, 2(9), 265-267.

[6] Renuka R, Devi C. 2007. Phytochemical characterization of defatted rice bran and optimization of process for their extraction and enrichment[J]. Bioresour Technol.98:3037-3043.

[7] Zhang, M.W., Zhang, R.F., Fang, Z.X., et al., 2005. Phenolic profiles and antioxidant activity of black rice bran of different commercially available varieties[J]. Agric Food Chem. 58 (13), 7580-7587.

[8] Han, X.L., Zhang, R.Y., Zhang, J., et al., 2007. Comprehensive Utilization of Rice Bran and Its Prospects[J]. Agricultural by-products Product processing.6 (7), 62-64.

[9] Hu, G.H., 2005. Application of food additives in grain and oil products[M]. Beijing: Chemical Industry Press Agency. 8 (9), 39-45.

[10] Wang Y, Wu SG, Xu W. The anti-tumor effect of rice bran polysaccharide and its partial mechanism [J]. Chinese Pharmacology Bulletin. 1999, 15 (1): 70 -72

[11] Qiu YH, Wu SG, Xu Wei. Extraction of rice bran polysaccharide and its immunomodulatory effect [J]. Chinese Journal of Biochemical Medicine. 1999, 20 (2): $91-93$

[12] Zheng XD, Zhou M, Fu CX. Optimization of the extraction process of polysaccharides from pearl barley [J]. Chinese Journal of Cereals and Oils, 2001, 15 (5): $19-22$

[13] Zhang Q, Jiang P. Research progress of polysaccharide function Food research and development [J]. 1998.9 (3): 11-13

[14]Newman R.K.et al Barley as a food grain [J].Cereal Food World.1991.36（9）: 806

[15]Wasserman B.P.el at. Hull less barley bran:a potential new product form and old grain[J] .Cereal food world, 1995.40 (11) : 819

[16]Tanigami Y. Partial degradation and biological activities of an anti-tumor polysaccharide form rice bran[J]. Chem Pharm Bull,1991,39 (7):1782-1787

[17]Takeda Y, Yoshikai Y, Ohga S, et al. Augmentation of host defense against bacte rial infection pretreated intraperitoneally with an alpha-glucan RBPs in mice $[\mathrm{J}]$. Immunopharmacol lmmunotoxicol,1990,12 (3) : 457-477 .

[18]Yamagishi T, Tsuboi T, Kikuchi K, et al. Potent natural immunomodulator, rice water-soluble polysaccharide fractions with anti-complementary activity [J].Cereal Chemistry, 2003,80 (1) : 5-8.

[19] Suguru T. Studies on an anti-tumor polysaccharide RBPs derive d from rice bran ( II ): perparation and general porperties of RON an active fraction of RBPs [J] . Chem Pharm Bull, 1988,36(9) : 3609-3613. 
[20] Zhao, M., Ding, X.L., 2006. Study on sweet potato sugar and white egg and white egg [J]. Food And Biotechnology Journal. 25 (1), 89-91.

[21] WangM, GaoY, XuD, etal. Hericiumerinaceus(Yamabushitake):a unique resource for developing functional foods and medicines [J].FoodFunction,2014,5(12): 3055-3064

[22]Hu Y, Cui C, Tao Q, Li W. The process optimization of hot water immersion and ethanol precipitation improves the extraction rate of Hericium erinaceus polysaccharide [J] .Chinese Seasoning, 2020,45 (1): 14-19.

[23] Huang, W.Y., Cai, Y.Z., Zhang, Y. 2009. Natural phenolic compounds from medicinal heRice bran polysaccharide (RBPs) and dietary plants: potential use for cancer prevention [J]. Nutr Cancer. 62 (1), 1-20.

[24] Chen, L, Li, Y.M., Chen, K.X., et al.,2013. Extraction and isolation of plant polyphenols Research progress [J]. Chinese Traditional and Herbal Medicine 28 (11), 1501-1507.

[25] Durcilece A S, Regina C M, Judith P A, et al., 2004. Carboxymethylation of cashew tree exudate polysaccharide[J].CarbohydratePolymers.58(2),163-171 .

[26] Falshaw R, Furneaux R H. 1998. Structural analysis of carrageenans from thetetrasporic stages of the red algae, Gigartina lanceata and Gigartina chapmanii ( Gigartinaceae, Rhodophyta ) [J ]. Carbohydrate Research. 307, 325-331.

[27] Mahner C, Lechner M D, Nordmeier E, 2001.Synthesis and characterization of dextran and pullulan sulphate [J]. Carbohydrate Research.5 (331), 203-208.

[28] M aciel J S, C haves L S, Souza B W S, et al. ,2008. Structural characterization of cold extracted fraction of soluble sulfated polysaccharide from red seaweed Gracilaria birdiae[J]. Carbohydrate Polymers, 71, 559-565.

[29] Cao HC. Determination of protein content by ultraviolet spectrophotometry [J]. Guangdong Chemical Industry, 2007 (08): 93-94

[30]J.Xu,W.Liu,W.B.Yao,X.B.Pang,D.K.Yin,X.D.Gao,Carboxymethylationofa polysaccharideextractedfromGanodermalucidumenhancesitsantioxidantactivitiesi nvitro,Carbohydr.Polym.78(2009)227-234.

[31]J.L.Wang,T.Yang,J.Tian,T.Zeng,X.F.Wang,J.Yao,J.Zhang,Z.Q.Lei,Synthesis andcharacterizationofphosphorylatedgalactomannan:theeffectofDSonsolutioncon formationandantioxidantactivities,Carbohydr.Polym.113(2014)325-335. 